\title{
Spatial patterns of epilepsy-related emergency department visits in California
}

\author{
Jim E. Banta, ${ }^{1}$ Askari Addison, ${ }^{2}$ W. Lawrence Beeson ${ }^{1}$ \\ ${ }^{1}$ School of Public Health, Loma Linda University, CA; ${ }^{2}$ Arizona Department of Health \\ Service, Phoenix, AZ, USA
}

Significance for public health

There have been few spatial analyses regarding treatment for epilepsy. This paper significantly expands upon previous work by simultaneously considering multiple urban centres and sparsely populated agricultural and desert/mountain areas in a large state. Furthermore, most epilepsy studies involve one system of care or funding source (such as Department of Veterans Affairs, Medicare, Medicaid, or private insurance plans). This paper considers all funding sources at community-based hospitals. Patient socio-demographics, area-based summaries of socio-demographics, and basic hospital characteristics explain most of the observed spatial variation in rates of emergency department (ED) visits related to epilepsy. However, preliminary spatial analysis demonstrated that an area within downtown Los Angeles did have a higher rate of epilepsy-related visits compared to the rest of the state. A more comprehensive surveillance approach with ED visit data could be readily applied to other large geographic areas and be useful both for on-going monitoring and public health intervention

\section{Abstract}

Background. Socio-demographic factors are associated with increased emergency department (ED) use among patients with epilepsy. However, there has been limited spatial analysis of such visits.

Design and methods. California ED visit at the patient ZIP Code level were examined using Kulldorf's spatial scan statistic to identify clusters of increased risk for epilepsy-related visits. Logistic regression was used to examine the relative importance of patient socio-demographics, Census-based and hospital measures.

Results. During 2009-2011 there were 29,715,009 ED visits at 330 hospitals, of which $139,235(0.5 \%)$ had epilepsy (International Classification of Disease-9 345.xx) as the primary diagnosis. Three large urban clusters of high epilepsy-related ED visits were centred in the cities of Los Angeles, Oakland and Stockton and a large rural cluster centred in Kern County. No consistent pattern by age, race/ethnicity, household structure, and income was observed among all clusters. Regression found only the Los Angeles cluster significant after adjusting for other measures.

Conclusions. Geospatial analysis within a large and geographically diverse region identified a cluster within its most populous city having an increased risk of ED visits for epilepsy independent of selected socio-demographic and hospital measures. Additional research is necessary to determine whether elevated rates of ED visits represent increased prevalence of epilepsy or an inequitable system of epilepsy care.

\section{Introduction}

Epilepsy is estimated to affect more than 65 million people worldwide, including approximately 2.2 million in the United States. ${ }^{1}$ Risk of epilepsy increases with age and is greater among those of lower socioeconomic status (SES) and ethnic minorities, particularly African Americans and Hispanics. ${ }^{2-5}$ Annual costs of epilepsy in the United States are estimated to be as high as 17.6 billion Dollars in direct and indirect costs. ${ }^{3}$ Both the United States government and the European Union Parliament have documented the need for additional research and treatment regarding epilepsy and acknowledged its negative impact on quality of life. ${ }^{1,6}$ It was estimated that seizures accounted for roughly one million emergency department (ED) visits annually or $1 \%$ of all ED visits in the United States and about $2 \%$ of visits to children's hospital emergency departments. ${ }^{7,8}$ However, the majority of ED visits for seizures involve patients without a prior history of epilepsy. Common non-epileptic causes of seizures among adult ED patients are alcohol withdrawal, stroke, tumour, trauma, and central nervous system infection. ${ }^{8}$ Measles-mumps-rubella (MMR) vaccine and measles-mumps-rubella-varicella (MMRV) vaccine administered after the first year of life are associated with an increased risk of seizures in children. ${ }^{9}$ Approximately $30 \%$ of epilepsy patients have medically intractable epilepsy, ${ }^{10}$ with $80 \%$ of the epilepsy-associated cost attributable to those patients. ${ }^{11}$ Though there are instances where ED care for epilepsy is appropriate, having an emergency department visit may be considered as unstable epilepsy, ${ }^{12}$ and higher rates of ED use may be indicative of poor care. Barriers to health care access have been observed affecting ED utilization by epilepsy patients in outpatient treatment and inpatient treatment. ${ }^{13,14}$ For example, an outpatient study series revealed that Blacks and Hispanics had higher rates of generalist visits, ED care and hospitalizations, and lower rates of specialist visits compared to whites. ${ }^{15}$ Furthermore, low SES patients consistently had higher use of ED care, more visits to general practitioners, a greater likelihood of having uncontrolled seizures, drug-related side effects, and a lower overall quality of life. ${ }^{13}$

Medications play a vital role in the management of epilepsy and may influence ED use in different ways. For example, higher total treatment costs are associated with generic anti-epileptic medications. ${ }^{16}$ Blacks and Hispanics are less likely to be diagnosed in neurology clinics and more likely to be prescribed suboptimal medications. ${ }^{17}$ In addition to disparities based on race/ethnicity, those who are uninsured or on public insurance are more likely than those with private insurance to receive suboptimal care, such as prescription of older medications or lack of treatment by a neurology specialist. ${ }^{13,15}$ Lower SES and insufficient insurance are also associated with poor compliance to treatment protocols. ${ }^{18}$ Non-adherence to anti-epileptic medications increases the likelihood of seizures, ${ }^{19}$ number of ED visits, ${ }^{16}$ and total healthcare costs. ${ }^{20,21}$ 
For the purpose of cost-conscious health care delivery, it is important to understand the factors contributing to the current costs of treatment in epilepsy-related diseases. Our study identifies a pertinent area of study missing in the literature: identifying areas of increased ED visits for epilepsy across a large area (state of California) and exploring areabased measures associated with the increased risk. This contributes to surveillance and control efforts by providing additional information for policymakers, researchers, clinicians and public health professionals. Such research is consistent with the Centres for Disease Control and Prevention definition of epilepsy as an emerging public health issue. ${ }^{22}$

\section{Design and methods}

\section{Data and measures}

California ED visit data were obtained for community-based hospitals, excluding federal hospitals. There were approximately 10 million ED visits per year between January 1, 2009 and December 310, 2011. Patient-level data included age group, gender, race/ethnicity, patient's home mailing address ZIP Code, expected source of payment, disposition of discharge, up to 25 diagnoses, and year treated. ${ }^{23}$ Each individual entry in the public-use data was de-identified. Before being released to researchers, some of these records had demographic data masked via a computerized protocol to prevent possible identification.

Area-based socio-demographic data were also obtained, ${ }^{24}$ which included U.S. Census 2010 information: percent of population within age groups, percent male/female, percent of population by race/ethnicity, percent of population living in households, and percent of household members which were not related to the head of household or were a relative other than a spouse or child. Data was also obtained from American Community Survey (ACS) supplements and included percent of population that is unemployed, household, family and per capita income, and percent of entire population as well as percent of families in poverty. Census and ACS data are provided by Zip Code Tabulation Areas (ZCTA), ${ }^{25}$ which are approximations of the ZIP Codes used for mail delivery by the U.S. Postal Service.

The hospital identification code, obtained from the ED visit data, was used as a proxy measure for the local healthcare system in the area data. Prior research with California hospital data found that using specific hospital identifiers in a regression model can explain more variation than hospital measures such as bed size and academic affiliation. ${ }^{26}$

\section{Subjects}

The study population ( $\mathrm{n}=139,235)$ used for this spatial analysis consists of ED visits having a primary diagnosis, i.e. main reason for visit and main diagnosis for billing, of epilepsy (International Classification of Disease, $9^{\text {th }}$ edition: ICD-9 codes $\left.345 . x x\right)$. A Canadian chart review confirmatory study found that an ICD-9 code of 345.xx in an emergency department or inpatient database had positive predictive values of $99 \%$ and $98 \%$ respectively. ${ }^{27}$

\section{Statistical analysis}

ArcGIS 10.1 (Esri, Redlands, CA, USA) software was used to combine the ED visit data with the ZIP Code-level area-based measures, matching on each patient's home ZIP Code. ED visits having missing or invalid ZIP Codes, such as for homeless patients or for patients residing outside of California, were dropped from further spatial analysis. The geocoded data contained 2525 ZIP codes some of which were used only for Post Office Box mail delivery, i.e. not associated with geographical area. Spatial analysis was restricted to the 1761 area-based ZIP Codes which had Census and ACS data.
SaTScan $^{\text {TM }}$ 9.1.1 (Martin Kulldorff, Boston, MA, USA - available at: www.satscan.org) was used for the cluster analysis of the geocoded and merged data obtained from ArcGIS 10.1. This program is well-documented in its ability to locate geographic clusters and has been used in prior analyses of California hospitalization data. ${ }^{28-31} \mathrm{~A}$ spatial-only scan of mutually exclusive clusters was done, with the numerator being epilepsy visits and the denominator being all ED visits. For the Bernoulli model used in this study, SaTScan selects a series of overlapping circles of varying sizes. ${ }^{30}$ The null hypothesis that all areas have equal incidence or population loads is tested by running a Monte Carlo simulation $(\mathrm{n}=999)$ of the data, in which those simulations exceeding the likelihood ratio are deemed significant as the simulation randomly samples geographic circles. ${ }^{30}$ These log likelihood levels are used by SaTScan to calculate the Monte Carlo rank for identifying significant clusters. Point estimates of relative risk is given for cases compared to all non-cases in the population, ${ }^{32}$ i.e. each cluster has a different reference population - all other geographic areas not included in the specific cluster. Significance levels and cluster coordinates given in the results section should be interpreted as estimates of the true magnitude and cluster location, not explicit empirical values. The cluster with the highest Monte Carlo ranking is considered the primary cluster, while all others are considered secondary clusters. ${ }^{33}$

Information from the SaTScan analysis (latitude and longitude for the centre of each identified cluster and distance of radius) was converted in ArcGIS into shaded circular areas for display purposes. Four large clusters were identified, using criteria of more than 1000 epilepsy cases and $\mathrm{P}<0.05$ significance level. We restricted the summary analysis to larger clusters for a number of reasons, such as differences in area measures, i.e. ZCTA vs. ZIP Code, some ED visits missing ZIP Code data, and irregular ZIP Code boundaries vs. circular cluster definition.

Chi-squared tests were used to identify differences in patient measures between the four clusters and the remainder of the State and Analysis of Variation tests to identify differences in area-based measures across clusters. A staged logistic regression analysis was conducted, to examine the impact of area-based measures, patient-level measures, hospital effects, and cluster designation on the likelihood that an ED visit would have epilepsy as a primary diagnosis. The relative contribution of each category of measures to the likelihood of an epilepsy diagnosis was assessed by receiver operator curve (ROC) analysis, successively entering each block of variables into the regression models and observing changes in the area under the curve. ${ }^{34}$ The regression analysis excluded ED visits which had unknown values of patient demographics (age, gender, race/ethnicity). SAS 9.3 software (SAS Institute, Gary, NC, USA) was used for this analysis. We did not use a Bonferroni correction for multiple corrections in presenting descriptive results as we were not doing classical hypothesis testing assuming a null difference, though the use of multi-level modelling and large sample size in the regression modelling should address concerns of multiple testing. ${ }^{35}$ Data processing, descriptive statistics, and spatial analysis occurred during calendar year 2013 while regression analysis and revision occurred during calendar year 2014.

\section{Results}

Table 1 presents demographics for the 29,715,009 million ED visits between 2009 and 2011. A total of 128,539 epilepsy discharges were successfully geocoded ( $92.3 \%$ of 139,235 discharges). Race/ethnicity was unknown for $14.6 \%$ of visits, gender for $8.9 \%$, and age group for $4.1 \%$ of visits. Managed care or private insurance was the primary payer source for $38.2 \%$ of visits, followed by Medicaid (in California known as Medi-Cal), which funded $28.2 \%$ of all visits.

Figure 1 represents all clusters from the SaTScan analysis, identified 
by the Monte Carlo rank. Not all of the State is shaded. Approximately $7 \%$ of the 1761 mapped ZIP Codes lacked ED discharges. Of the remaining 1639 ZIP codes with any ED data, only 117 ZIP codes were identified by SatScan as being within a cluster of higher risk. Of the 22 clusters identified by SatScan, 15 were significant at the 0.05 level and 13 at the 0.01 level. For those ZIP Codes which are very small or have no radius, only a number will appear. The large clusters were located at the following latitude/longitude coordinates: cluster 1 (the primary cluster), Los Angeles: 33.975750 N, 118.250945 W; cluster 2, Kern County: 35.705086 N, 117.831690 W; cluster 3, Oakland: $37.804169 \mathrm{~N}, 122.282528 \mathrm{~W}$; and cluster 7, Stockton: $38.036780 \mathrm{~N}, 121.347274 \mathrm{~W}$.

Table 2 presents SaTScan details for the clusters having more than 1000 epilepsy cases. The relative risks for cluster 1 (Los Angeles), cluster 2 (Kern County), cluster 3 (Oakland) and cluster 7 (Stockton) were $1.62,1.32,1.44$, and 1.21 , respectively, indicating a $62 \%, 32 \%, 44 \%$, and $21 \%$ greater risk of being an ED discharge with an epilepsy diagnosis. For comparison, the total population of California in 2010 was $37,253,956$ persons and there were 29,715,009 ED visits between 2009 and 2011. If one divides the annual average ED visits, as shown in Table 1 , by total population, then $26.6 \%$ of the population in the State had an ED visit each year during the study period (if each person frequents the ED only once per year). The calculated percentages of annual ED visits per population for clusters $1,2,3,7$, and remainder of the State were $8.6 \%, 16.4 \%, 25.4 \%, 14.5 \%$, and $28.6 \%$, respectively. Thus all epilepsy clusters have less overall ED utilization compared to the rest of the State.

Table 3 presents demographics for epilepsy discharges by cluster, excluding cases with missing or masked data. There were statistically significant differences $(\mathrm{P}<0.001)$ across clusters for all variables. Three of the clusters had a higher percentage of Hispanic epilepsy discharges compared to the rest of the State, with only the Los Angeles cluster (30.4\%) being lower than 35.3\% for the rest of California. All clusters had a lower percentage of Black discharges compared to the rest of the State and there was a majority of females throughout the State. The Stockton cluster was notable for having the highest percentage of Medicaid (40.6\%), Hispanics (70.4\%), and patients less than 18 years of age (33.6\%).

Table 4 contains area-based measures for each of the four main clusters and the remainder of the State. As with the previous Table, all differences were significant at the $\mathrm{P}<0.001$ level. Consistent with Table 3 , the Stockton Cluster had the highest percentage of its population less than 18 years of age (28.7\%), Hispanic or Latino (73.9\%), and the lowest income. Also consistent with Table 3, all clusters had a lower percentage of Black/African Americans compared to the rest of the State. Approximately $98 \%$ of the population lived in households. Those not in households might be homeless or living in group quarters as in prisons, long-term care facilities, and the armed forces. Approximately 18\% of those living in households were not immediately related to the head of household, with the highest percent being in the Stockton cluster $21.8 \%$. The Stockton and Oakland clusters had lower income than the remainder of the State on all three measures of income. The Inyo-Kern Cluster's average income was roughly equal to the rest of the State. The Los Angeles Cluster had higher income, the lowest unemployment rate, and the lowest percent of poverty. The Oakland Cluster had the highest percentage of poverty and unemployment.

Table 5 presents the odds ratios for the full model logistic regression model. Only the primary cluster (Los Angeles) had a significantly higher likelihood (Odds Ratio, OR 1.06) of an epilepsy diagnosis. Compared to managed care/private insurance, all other payer types were associated with an increased risk, particularly the government programs of Medicare (OR 2.44) and Medicaid (OR 1.55). Blacks (OR 1.20) were more likely than Whites to have an epilepsy diagnosis and females less likely (OR 0.59) than males. Adults were at greater risk compared to children/adolescents, except for those 65 years of age and greater (OR
Table 1. Descriptive statistics for California Emergency Department visits $(\mathrm{n}=29,715,009)$.

\begin{tabular}{|c|c|c|}
\hline Variable & Frequency & $\%$ \\
\hline Non-epilepsy discharges & $29,575,774$ & 99.5 \\
\hline Epilepsy discharges & 139,235 & 0.5 \\
\hline Geocoded epilepsy discharges & 128,539 & 0.5 \\
\hline $\begin{array}{l}\text { Race/ethnicity } \\
\text { Hispanic } \\
\text { Asian } \\
\text { Black } \\
\text { White } \\
\text { Non-Hispanic, other } \\
\text { Unknown/masked } \\
\end{array}$ & $\begin{array}{c}9,122,995 \\
855,140 \\
2,766,190 \\
11,261,345 \\
1,369,461 \\
4,339,878\end{array}$ & $\begin{array}{c}30.7 \\
2.9 \\
9.3 \\
37.9 \\
4.6 \\
14.6\end{array}$ \\
\hline $\begin{array}{l}\text { Gender } \\
\text { Female } \\
\text { Male } \\
\text { Unknown/masked }\end{array}$ & $\begin{array}{c}14,860,757 \\
12,222,647 \\
2,631,605\end{array}$ & $\begin{array}{l}50.0 \\
41.1 \\
8.9\end{array}$ \\
\hline $\begin{array}{l}\text { Age } \\
\qquad \begin{array}{l}0-17 \\
18-34 \\
35-64 \\
65+ \\
\text { Unknown/masked }\end{array}\end{array}$ & $\begin{array}{l}7,622,926 \\
7,565,350 \\
9,773,944 \\
3,529,710 \\
1,223,079\end{array}$ & $\begin{array}{c}26.6 \\
25.5 \\
32.9 \\
11.9 \\
4.1\end{array}$ \\
\hline $\begin{array}{l}\text { Year } \\
2009 \\
2010 \\
2011\end{array}$ & $\begin{array}{c}9,868,913 \\
9,730,448 \\
10,115,648\end{array}$ & $\begin{array}{l}33.2 \\
32.8 \\
34.0\end{array}$ \\
\hline $\begin{array}{l}\text { Payer source } \\
\text { Medicaid } \\
\text { Medicare } \\
\text { Managed care or private insurance } \\
\text { Self-pay } \\
\text { Other insurance }\end{array}$ & $\begin{array}{c}8,363,720 \\
3,005,006 \\
11,359,091 \\
5,056,147 \\
1,931,045\end{array}$ & $\begin{array}{l}28.2 \\
10.1 \\
38.2 \\
17.0 \\
6.5\end{array}$ \\
\hline $\begin{array}{l}\text { Cluster ID } \\
\text { Rest of State } \\
1 \text { Los Angeles } \\
2 \text { Iny-Kern } \\
3 \text { Oakland } \\
7 \text { Stockton }\end{array}$ & $\begin{array}{c}27,419,572 \\
533,803 \\
988,895 \\
586,096 \\
186,643\end{array}$ & $\begin{array}{r}92.7 \\
1.8 \\
3.3 \\
2.0 \\
0.6\end{array}$ \\
\hline
\end{tabular}

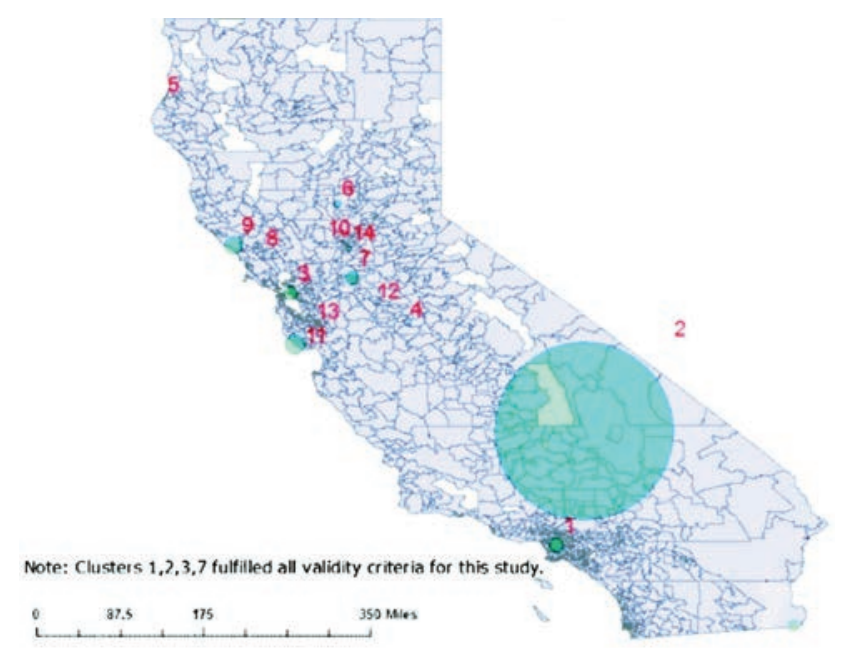

Figure 1. Epilepsy clusters in California Emergency Department discharges, 2009-2011. Background shading is for 1639 ZIP codes which had any emergency department discharges during the study period. 
0.57). With all patient-level measures included in the full model, the only area-based measures significantly associated with epilepsy ED risk were household structure. Epilepsy ED risk decreased slightly as more of the population lived in households and increased slightly with an increase in percent of household members not immediately related to head of household. Not shown are the results of the staged logistic regression analysis. Note from Table 5 that the full model's c-statistic or area under the curve (AUC) has a modest value of 0.695 (where 0.500 means the model is no better than guessing the outcome and 1.000 means the model perfectly predicts the outcome. Model discrimination, roughly equivalent to explained variation is $0.695-0.500=0.195$. Patient measures accounted for $55.4 \%(0.108 / 0.195)$ of the explained variation. Hospital identification code accounted for $23.6 \%$ $(0.046 / 0.195)$ and area-based measures for $17.9 \%(0.035 / 0.195)$ of variation. There was a modest effect over time (3.1\% of explained variation due to year of visit).

\section{Discussion}

Examining the geographic variation in patterns of care is an emerging methodology for studying public health burden. Though such an approach has been used with a number of other conditions, such as cancer and stroke, ${ }^{8}$ there have been few studies examining spatial patterns of care for epilepsy. Most research to date has evaluated care within one or two cities, not larger geographical units such as at the state level. A large and diverse state such as California is ideal for applying this approach to assessment of public health burden. A detailed spatial analysis of epilepsy-related ED utilization in California directly addresses questions of how to more accurately assess the public health burden for patients and families. ${ }^{1}$

Spatial analysis found four large clusters of increased relative risk of ED visits related to epilepsy in separate regions of California. As might

Table 2. SaTScan cluster results for Emergency Department epilepsy visits 2009-2011 with valid ZIP Codes.

\begin{tabular}{lccccc} 
& Cluster 1 & Cluster 2 & Cluster 3 & \multicolumn{2}{c}{ Cluster 7 } \\
Epilepsy cases & 12,606 & 11,029 & 4946 & 1560 & 98,398 \\
Census 2010 population & $2,064,824$ & $2,014,626$ & 767,984 & 429,220 & $31,977,302$ \\
\hline Log likelihood ratio & $1,157.1$ & 368.4 & 287.7 & 25.7 & $\mathrm{~N} / \mathrm{A}$ \\
Expected & 8106.9 & 8512.2 & 3468.8 & 1295.5 & $\mathrm{~N} / \mathrm{A}$ \\
\hline Observed/expected & 1.55 & 1.30 & 1.43 & 1.20 & $\mathrm{~N} / \mathrm{A}$ \\
Relative risk & 1.62 & 1.32 & 1.44 & $<1(10-8)$ & 1 \\
\hline P-value & $<1(10-17)$ & $<1(10-17)$ & $<1(10-17)$ & 12.05 & $\mathrm{~N} / \mathrm{A}$ \\
Cluster radius length, Km & 11.12 & 152.16 & 12.2 & $\mathrm{~N} / \mathrm{A}$ \\
\hline
\end{tabular}

Cluster 1: Los Angeles; Cluster 2: Inyo-Kern; Cluster 3: Oakland; Cluster 7: Stockton. N/A, not available. Relative risk given in Table 2 is in regards to referenced individuals in cluster ZIP Codes, given all others present outside the cluster. Thus each relative risk has a different reference population because, for example cluster l's reference includes individuals in cluster 2,3 , and 7.

Table 3. Patient demographics for Emergency Department visits having complete data.

\begin{tabular}{|c|c|c|c|c|c|c|}
\hline & $\begin{array}{l}\text { Cluster } 1 \\
(460,661)\end{array}$ & $\begin{array}{r}\text { Cluster } 2 \\
(869,793)\end{array}$ & $\begin{array}{l}\text { Cluster } 3 \\
(525,620)\end{array}$ & $\begin{array}{l}\text { Cluster } 7 \\
(168,556)\end{array}$ & $\begin{array}{c}\text { Rest of CA } \\
(23,349,827)\end{array}$ & $\mathbf{P}$ \\
\hline Epilepsy as primary diagnosis & 0.57 & 0.42 & 0.40 & 0.50 & 0.47 & $<0.001$ \\
\hline $\begin{array}{l}\text { Payer source } \\
\text { Medicaid } \\
\text { Medicare } \\
\text { Managed care/private insurance } \\
\text { Self-pay } \\
\text { Other insurance type } \\
\end{array}$ & $\begin{array}{c}26.1 \\
9.4 \\
42.2 \\
14.9 \\
7.5\end{array}$ & $\begin{array}{l}30.3 \\
12.2 \\
34.6 \\
15.5 \\
7.5\end{array}$ & $\begin{array}{c}35.6 \\
11.3 \\
33.0 \\
13.7 \\
6.4\end{array}$ & $\begin{array}{c}40.6 \\
9.6 \\
29.0 \\
16.1 \\
4.7\end{array}$ & $\begin{array}{l}30.0 \\
10.0 \\
36.8 \\
16.8 \\
6.4\end{array}$ & $<0.001$ \\
\hline $\begin{array}{l}\text { Race/ethnicity } \\
\text { White } \\
\text { Hispanic } \\
\text { Asian } \\
\text { Black } \\
\text { Other }\end{array}$ & $\begin{array}{l}52.2 \\
30.4 \\
2.7 \\
8.8 \\
5.8\end{array}$ & $\begin{array}{l}41.9 \\
42.9 \\
4.4 \\
5.5 \\
5.2\end{array}$ & $\begin{array}{c}32.6 \\
49.2 \\
2.9 \\
10.5 \\
4.8\end{array}$ & $\begin{array}{l}21.8 \\
70.4 \\
1.8 \\
2.7 \\
3.3\end{array}$ & $\begin{array}{c}44.7 \\
35.3 \\
3.4 \\
11.2 \\
5.4\end{array}$ & $<0.001$ \\
\hline $\begin{array}{l}\text { Gender } \\
\text { Male } \\
\text { Female }\end{array}$ & $\begin{array}{l}44.0 \\
56.0\end{array}$ & $\begin{array}{l}44.5 \\
55.5 \\
\end{array}$ & $\begin{array}{l}44.0 \\
56.0\end{array}$ & $\begin{array}{l}44.2 \\
55.8 \\
\end{array}$ & $\begin{array}{l}45.0 \\
55.0\end{array}$ & $<0.001$ \\
\hline $\begin{array}{l}\text { Age } \\
\qquad \begin{array}{l}0-17 \\
18-34 \\
35-64 \\
65+\end{array}\end{array}$ & $\begin{array}{l}26.2 \\
26.8 \\
33.5 \\
13.4\end{array}$ & $\begin{array}{l}30.5 \\
26.2 \\
31.7 \\
11.7\end{array}$ & $\begin{array}{l}28.4 \\
26.4 \\
32.4 \\
12.9\end{array}$ & $\begin{array}{l}33.6 \\
26.0 \\
28.6 \\
11.8\end{array}$ & $\begin{array}{c}<0.001 \\
27.2 \\
26.7 \\
34.2 \\
12.0\end{array}$ & \\
\hline $\begin{array}{l}\text { Year } \\
2009 \\
2010 \\
2011 \\
\end{array}$ & $\begin{array}{l}33.3 \\
32.4 \\
34.4 \\
\end{array}$ & $\begin{array}{l}33.3 \\
32.8 \\
33.8 \\
\end{array}$ & $\begin{array}{l}33.5 \\
32.7 \\
33.8 \\
\end{array}$ & $\begin{array}{l}33.9 \\
33.2 \\
32.9 \\
\end{array}$ & $\begin{array}{l}33.2 \\
32.7 \\
34.1 \\
\end{array}$ & $<0.001$ \\
\hline
\end{tabular}

Cluster 1: Los Angeles; Cluster 2: Inyo-Kern; Cluster 3: Oakland; Cluster 7: Stockton. 
be expected, many of the clusters were located in areas of high population, with clusters in the San Francisco Bay Area (Oakland Cluster), Sacramento Valley (Stockton Cluster), and greater Los Angeles. However, not all of the high population areas were selected, such as Orange and San Diego counties. Furthermore, a large cluster was cantered in the rural Inyo-Kern Census-designated place in Kern County.

There was general agreement between patient and area-based measures. For example, the Stockton cluster had the highest percentage of epilepsy ED discharges for patients less than 18 years of age and the highest percent of Hispanic discharges. Based on Census 2010 data, the Stockton cluster also had the highest percentage of youth and Hispanic residents. Most clusters had a higher than rest-of-State percentage of Hispanics, except for the Los Angeles cluster. In examining the area-based table, it is clear that there is not a monolithic trend. For example, not every epilepsy cluster had worse economic measures compared to the rest of the state. Nor were there consistent trends based on age, race, or household structure.

The regression findings differed from the SatScan analysis in that only the primary cluster (Los Angeles) had a significantly higher risk. There are at least two reasons for this difference. A technical reason has to do with differing reference groups. The SatScan analysis defined each cluster by itself, with everyone not in that cluster serving as the reference group. In contrast the regression's reference group was defined as everyone not already in a cluster. More importantly, the regression accounted for differences in patient characteristics, areabased characteristics, and a crude measure of the healthcare system, unlike the SatScan analysis. The apparent protective effect of clusters 2 and 3 in the regression analysis is likely due to cluster differences in patient characteristics, hospital characteristics, and area-based sociodemographics.

The observation that area-based summaries of patient characteristics generally reflected Census measures suggests an indirect route by which an area's socio-demographics influenced ED use. Census measures by themselves had accounted for $17.9 \%$ of the explained variation in the staged logistic regression analysis. However, once patient characteristics (age, race, gender, and source of payment) were included, household composition was the only Census measure that remained statistically significant, i.e. area-based measures of age, race/ethnicity, gender, income, poverty, and unemployment were no longer predictive of a particular ED visit being for treatment of epilepsy.

Beyond socio-demographics, healthcare measures of an area are also important as suggested by the finding that a simple measure of the healthcare system (a code identifying each hospital) accounted for $23.6 \%$ of explained variation in epilepsy-related ED visits. The higher rate of epilepsy-related visits within the clusters, especially the Los Angeles cluster, may indicate a lack of access to tertiary care specialists and perhaps also greater access to emergency departments. It is also possible that the 330 hospital identifiers are picking up variation in coding practices of physicians in addition to actual differences in care. With these data one can only make statements regarding ED usage, not prevalence of epilepsy. Additional data would be needed to determine if indeed it is differences in access to specialists that explain some of the variation in ED usage.

More clearly identifying areas of potentially suboptimal care may contribute to better preventive strategies in those underserved communities and empower community organizations in those areas to mobilize to assist for services and screening for epilepsy. Indeed, a search in PubMed found only a few citations for geographic information systems and epilepsy, with studies based in Sardinia and rural Kenya. ${ }^{36,37}$ A United States study examined data from five hospitals in Philadelphia, Pennsylvania, with the goals of highlighting overall significant disparities in epilepsy risks between Whites, Blacks, and Hispanics. ${ }^{5}$ The authors concluded that GIS could reveal spatial patterns in patient data and highlight areas of disparity in epilepsy risk among subgroups of the population. ${ }^{5}$ This paper significantly expands upon previous work by simultaneously considering multiple urban centres and sparsely populated agricultural and desert/mountain areas. Furthermore, most non-spatial epilepsy studies involve one system of care or funding source (Department of Veterans Affairs, Medicare, Medicaid, or private insurance plans), while this paper considers all funding sources at community-based hospitals. Population-based studies tend to be either large surveys or analyses of national datasets, typically without having detailed geographic location.

There was a modest finding regarding increased risk of epilepsyrelated ED visits with decreasing percentage of population living in households and risk increasing with increasing diversity within house-

Table 4. Area-based measures for Emergency Department visits.

\begin{tabular}{|c|c|c|c|c|c|c|}
\hline & Cluster 1 & Cluster 2 & Cluster 3 & Cluster 7 & Rest of CA & $\mathbf{P}$ \\
\hline Female, $\%$ & 50.2 & 49.9 & 50.6 & 50.6 & 50.3 & $<0.001$ \\
\hline $\begin{array}{l}\text { Age } \\
\begin{array}{l}0-17 \\
18-54 \\
55+\end{array}\end{array}$ & $\begin{array}{l}24.1 \\
54.5 \\
21.5\end{array}$ & $\begin{array}{l}27.5 \\
51.4 \\
21.1 \\
\end{array}$ & $\begin{array}{l}26.7 \\
52.8 \\
20.5 \\
\end{array}$ & $\begin{array}{l}28.7 \\
51.5 \\
19.8\end{array}$ & $\begin{array}{l}25.8 \\
52.5 \\
21.7 \\
\end{array}$ & $\begin{array}{l}<0.001 \\
<0.001 \\
<0.001\end{array}$ \\
\hline $\begin{array}{l}\text { Race/ethnicity } \\
\text { White } \\
\text { Hispanic or Latino } \\
\text { Asian } \\
\text { Black/African American } \\
\text { Other race }\end{array}$ & $\begin{array}{c}43.4 \\
37.0 \\
9.4 \\
6.3 \\
3.9\end{array}$ & $\begin{array}{c}34.7 \\
46.0 \\
12.2 \\
4.0 \\
3.2\end{array}$ & $\begin{array}{l}27.2 \\
53.2 \\
10.1 \\
6.7 \\
2.9\end{array}$ & $\begin{array}{c}15.3 \\
73.9 \\
7.1 \\
1.8 \\
1.9\end{array}$ & $\begin{array}{c}37.6 \\
41.2 \\
10.6 \\
6.9 \\
3.7\end{array}$ & $\begin{array}{l}<0.001 \\
<0.001 \\
<0.001 \\
<0.001 \\
<0.001\end{array}$ \\
\hline Percent of population in households & 97.4 & 98.3 & 98.0 & 99.1 & 97.9 & $<0.001$ \\
\hline Percent of households not immediate family & 16.8 & 17.8 & 18.4 & 21.8 & 18.1 & $<0.001$ \\
\hline Median family income, $\$$ & 71,544 & 66,672 & 61,345 & 52,790 & 66,143 & $<0.001$ \\
\hline Mean household income, $\$$ & 77,876 & 77,200 & 69,574 & 62,938 & 74,398 & $<0.001$ \\
\hline Per capita income, $\$$ & 28,275 & 25,968 & 24,094 & 19,202 & 26,305 & $<0.001$ \\
\hline All people in poverty, $\%$ & 13.6 & 17.0 & 18.2 & 15.6 & 16.5 & $<0.001$ \\
\hline All families in poverty, \% & 10.3 & 13.9 & 15.3 & 13.4 & 13.2 & $<0.001$ \\
\hline Unemployment rate & 9.4 & 11.5 & 11.7 & 11.6 & 11.3 & $<0.001$ \\
\hline
\end{tabular}


Table 5. Logistic regression for primary diagnosis of epilepsy among California Emergency Department visits (n=24,830,670).

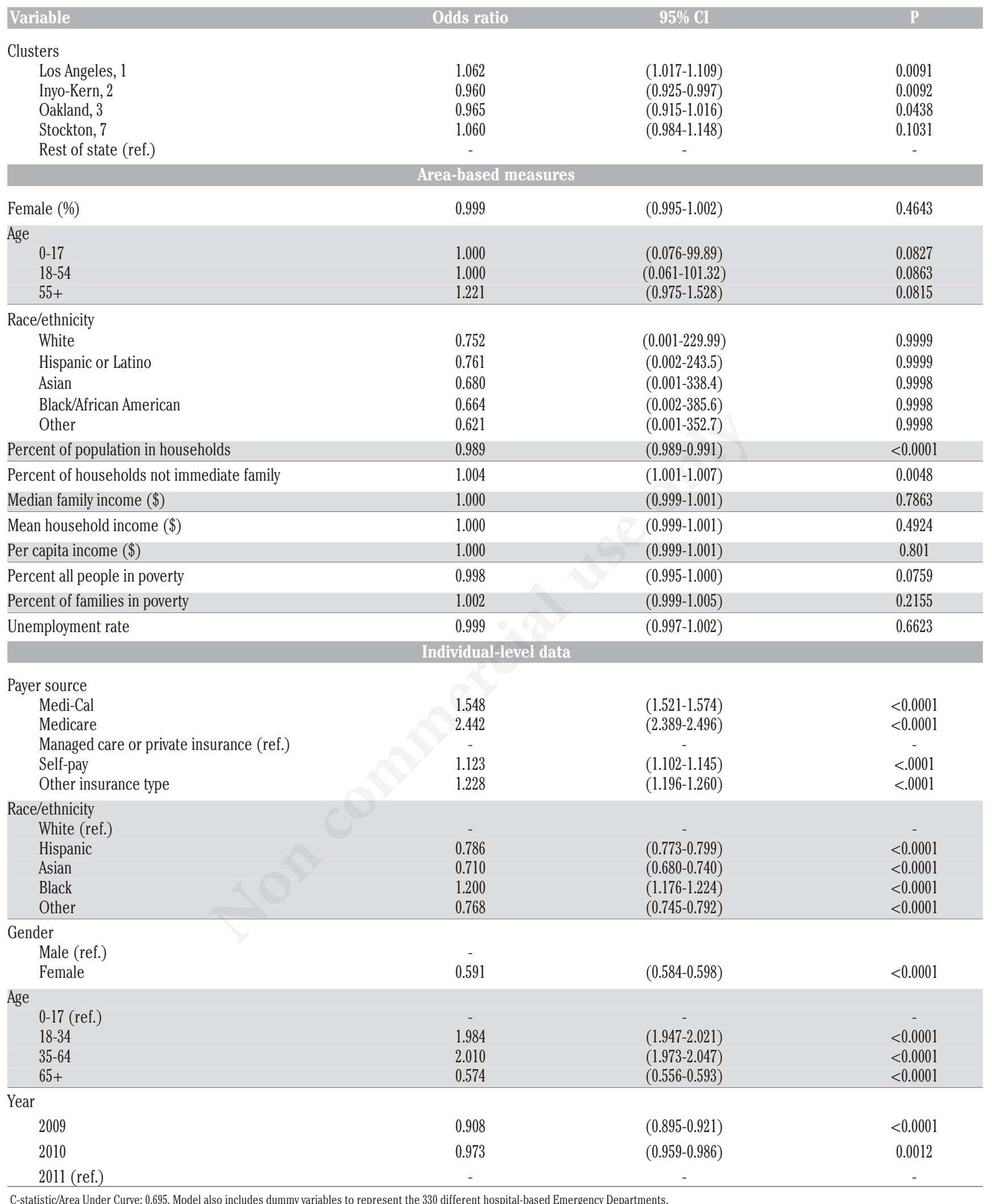

C-statistic/Area Under Curve: 0.695. Model also includes dummy variables to represent the 330 different hospital-based Emergency Departments. 
holds, i.e. not immediate relatives of the householder. We must temper analysis of neighbourhood effects based on Census data with the observation that roughly nine percent of cases were patients either homeless or not residents of California. However, since those cases were excluded for all other analyses involving area-based measures, it is likely that this measure of social cohesion/disorder is significantly related to epilepsy-related ED usage. Further research could explore neighbourhood effects more strongly associated with epilepsy prevalence and acute care.

In addition to analysis of ED visit data to better understand relationships with the social environment, it is also being recognized that ED's can be used for on-going surveillance, as with infectious diseases. ${ }^{38}$ Such a public health effort is beyond the scope of this preliminary analysis and would need to consider the effects of looking at unique patients rather than all visits and also empirically determine which time frames would be most reasonable for determining clusters. ${ }^{39}$ Ongoing examination of regional data may be useful from a policy perspective by documenting changes resulting from the Patient Protection and Affordable Care Act (PPACA). Indeed, it has been argued that medical geography can play a crucial role in the implementation of PPACA, particularly in connecting public health disease surveillance to enhanced patient care outcomes. ${ }^{40}$ Surveillance may also have clinical implications, for example, monitoring the effects of changes in medication practice. Determining if specific clusters exist primarily due to multiple visits of a handful of patients or individual visits of many different patients could result in different interventions, such as general provider education or a hospital-based system of tracking high-visit patients.

\section{Limitations}

Methodological limitations include our usage of ZIP Codes and ZCTAs. ZIP codes, as noted earlier, have irregular, variable areas. They are not an optimal level of measurement since they may change in population, demographics, and even size and shape over time may not be homogoenous with respect to sociodemographics. However, we were constrained to work with ZIP Codes because that is the geographic measure available in the hospital dataset. Others have used ZIP Code data to effectively study characteristics associated with inpatient use. ${ }^{41}$ Another limitation related to ZIP Codes is that the geographic center of a cluster identified by SatScan analysis may not correspond to the population center of an area. This is limited problem for the three study clusters located in urban areas which have a radius of 11 to 12 kilometers. This could be more of a concern for the Inyo-Kern Cluster which is located in a rural area and has a cluster radius of 152 kilometers. Such a large geographic cluster is also more likely to be heterogenous, i.e. have some areas with lower risk. ${ }^{33}$

Perhaps the most significant limitation for this analysis is the nature of public-use data. For example, masking of demographic data prevented measurement of gender and race for all epilepsy visits. More challenging is that the ED visit data were de-identified. An individual could have multiple discharges, each of which is treated as an independent entry in this analysis. In addition to possible violation of the regression assumption of independence, the more serious problem is that with public-use data we are unable to identify which patients have multiple ED visits related to epilepsy. Including all visits of epilepsy patients could result in different clusters being identified compared to using just one record per patient. ${ }^{39}$ Though it is not possible to assess repeat ED visits with this dataset, a study of seven hospitals in Manhattan, New York found that $22 \%$ of patients used more than one hospital during a two year period. ${ }^{42}$ However, the large number of subjects ( $n=29$ million for SatScan and nearly 25 million for regression) lends credence to these preliminary findings. Excluding small clusters (based on case total) reduces the possibility of an identified spatial scan cluster being based primarily on a small handful of individuals having multiple ED visits. Furthermore, the use of Census data allows for clear socio-demographic characterization of the population within the large identified clusters and demonstrates that patterns of patient socio-demographics generally followed Census patterns. It bears repeating that this is an analysis of epilepsy-related ED utilization within a geographical area, not a clinical study or a determination of epilepsy prevalence.

\section{Conclusions}

Preliminary spatial analysis identified a handful of large clusters within California having higher rates of ED visits for epilepsy. These clusters are not simply population artefacts, nor are they solely composed of poor, urban zones, but are located in distinct regions of California with different ethnic, economic, and demographic distributions. Non-spatial regression, adjusting for other factors such as patient demographics and the healthcare system, suggested that only the primary cluster in Los Angeles remained as having increased risk of epilepsy ED visits. More sophisticated spatial analysis, along with data having unique patient identifiers, is needed to determine if areas identified as having elevated rates of ED visits represent regions with an excess of epilepsy patients, or if those regions have an inequitable system of epilepsy care.

Correspondence: Jim E. Banta, Loma Linda University School of Public Health, 24951 North Circle Drive, Loma Linda, CA 92350, USA.

Tel.: +1.909.558.7753 - Fax: +1.909.558.0469.

E-mail: jbanta@llu.edu

Key words: epilepsy, emergency department, Geographic Information Systems, surveillance, California.

Contributions: JEB, AA, WLB, designing the study, drafting or revising the manuscript, approving the final version; JEB, data collection, processing, and statistical analysis; AA, spatial analysis and initial preparing of descriptive tables.

Conflict of interest: the authors declare no potential conflict of interest.

Received for publication: 4 November 2014.

Accepted for publication: 10 February 2015.

(C) Copyright J. E. Banta et al., 2015

Licensee PAGEPress, Italy

Journal of Public Health Research 2015;4:441

doi:10.4081/jphr.2015.441

\section{References}

1. Institute of Medicine. Epilepsy across the spectrum: promoting health and understanding. Washington, DC: The National Academies Press; 2012.

2. Hesdorffer DC, Logroscino G, Benn EK, et al. Estimating risk for developing epilepsy: a population-based study in Rochester, Minnesota. Neurology 2011;76:23-7.

3. Epilepsy Foundation of America. Incidence and Prevalence 2012. Available from: http://www.epilepsyfoundation.org/aboutepilepsy/ whatisepilepsy/statistics.cfm. Accessed on: October, 2014.

4. Kelvin EA, Hesdorffer DC, Bagiella E, et al. Prevalence of selfreported epilepsy in a multiracial and multiethnic community in New York City. Epilepsy Res 2007;77:141-50.

5. Wheeler DC, Waller LA, Elliott J0. Modeling epilepsy disparities among ethnic groups in Philadelphia, PA. Stat Med 2008;27:406985 . 
6. Baulac M, De Boer H, Elger C, et al. The written declaration on epilepsy: an important achievement for Europe and beyond. Seizure 2012;21:75-6.

7. Pallin DJ, Goldstein JN, Moussally JS, et al. Seizure visits in US emergency departments: epidemiology and potential disparities in care. Int J Emerg Med 2008;1:97-105.

8. Martindale JL, Goldstein JN, Pallin DJ. Emergency department seizure epidemiology. Emerg Med Clin North Am 2011;29:15-27.

9. Hambidge SJ, Newcomer SR, Narwaney KJ, et al. Timely versus delayed early childhood vaccination and seizures. Pediatrics 2014;133:e1492-9.

10. Kwan P, Brodie MJ. Early identification of refractory epilepsy. New Engl J Med 2000;342:314-9.

11. Begley CE, Famulari M, Annegers JF, et al. The cost of epilepsy in the United States: an estimate from population-based clinical and survey data. Epilepsia 2000;41:342-51.

12. Labiner DM, Paradis PE, Manjunath R, et al. Generic antiepileptic drugs and associated medical resource utilization in the United States. Neurology 2010;74:1566-74.

13. Begley C, Basu R, Lairson D, et al. Socioeconomic status, health care use, and outcomes: persistence of disparities over time. Epilepsia 2011;52:957-64.

14. Farhidvash F, Singh P, Abou-Khalil B, Arain A. Patients visiting the emergency room for seizures: insurance status and clinic followup. Seizure 2009;18:644-7.

15. Begley CE, Basu R, Reynolds T, et al. Sociodemographic disparities in epilepsy care: results from the Houston/New York City health care use and outcomes study. Epilepsia 2009;50:1040-50.

16. Helmers SL, Paradis PE, Manjunath R, et al. Economic burden associated with the use of generic antiepileptic drugs in the United States. Epilepsy Behav 2010;18:437-44.

17. Hope OA, Zeber JE, Kressin NR, et al. New-onset geriatric epilepsy care: race, setting of diagnosis, and choice of antiepileptic drug. Epilepsia 2009;50:1085-93.

18. Burneo JG, Jette N, Theodore W, et al. Disparities in epilepsy: report of a systematic review by the North American Commission of the International League Against Epilepsy. Epilepsia 2009;50:2285-95.

19. Manjunath R, Davis KL, Candrilli SD, Ettinger AB. Association of antiepileptic drug nonadherence with risk of seizures in adults with epilepsy. Epilepsy Behav 2009;14:372-8.

20. Ettinger AB, Manjunath R, Candrilli SD, Davis KL. Prevalence and cost of nonadherence to antiepileptic drugs in elderly patients with epilepsy. Epilepsy Behav 2009;14:324-9.

21. Faught RE, Weiner JR, Guerin A, et al. Impact of nonadherence to antiepileptic drugs on health care utilization and costs: findings from the RANSOM study. Epilepsia 2009;50:501-9.

22. Centers for Disease Control and Prevention. Targeting epilepsy: improving the lives of people with one of the nation's most common neurological conditions, at a glance. 2011. Available from: http:/www.cdc.gov/chronicdisease/resources/publications/aag/epil epsy.htm. Accessed: October, 2014.

23. Office of Statewide Health Planning and Development. Healthcare information division: emergency department and ambulatory sur- gery data. 2013. Available from: http://www.oshpd.ca.gov/ HID/Products/EmerDeptData/. Accessed: January, 2014.

24. California Department of Finance. State data center, demographic research. 2013. Available from: http://www.dof.ca.gov/research/ demographic/. Accessed: January, 2014.

25. United States Department of Commerce. ZCTA definition. Available from: http://www.census.gov/geo/reference/zctas.html. Accessed: 16, 2014.

26. Banta JE, Joshi KP, Beeson L, Nguyen HB. Patient and hospital characteristics associated with inpatient severe sepsis mortality in California, 2005-2010. Crit Care Med 2012;40:2960-6.

27. Jette N, Reid AY, Quan H, et al. How accurate is ICD coding for epilepsy? Epilepsia 2010;51:62-9.

28. Jones SG, Kulldorff M. Influence of spatial resolution on space-time disease cluster detection. PloS One 2012;7:e48036.

29. Kulldorff M. A spatial scan statistic. Commun Stat Theor M 1997;26:1481-96.

30. Kulldorff M, Nagarwalla N. Spatial disease clusters: detection and inference. Stat Med 1995;14:799-810.

31. Banta JE, Wiafe S, Soret S, Holzer C. A spatial needs assessment of indigent acute psychiatric discharges in California. J Behav Health Serv Res 2008;35:179-94.

32. Kulldorff M. SaTSan User Guide for Version 9.0. 2010. Available from: http://www.kaspersky.com/downloads/internet-security

33. Chen J, Roth RE, Naito AT, et al. Geovisual analytics to enhance spatial scan statistic interpretation: an analysis of US cervical cancer mortality. Int J Health Geogr 2008;7:57.

34. Hanley JA, McNeil BJ. The meaning and use of the area under a receiver operating characteristic (ROC) curve. Radiology 1982;143:29-36.

35. Gelman A, Hill J, Yajima M. Why we (usually) don't have to worry about multiple comparisons. J Res Educ Eff 2012;5:189-211.

36. Cossu P, Deriu MG, Casetta I, et al. Epilepsy in Sardinia, insular Italy: a population-based prevalence study. Neuroepidemiology 2012;39:19-26.

37. Ngugi AK, Bottomley C, Fegan G, et al. Premature mortality in active convulsive epilepsy in rural Kenya: causes and associated factors. Neurology 2014;82:582-9.

38. Hiller KM, Stoneking L, Min A, Rhodes SM. Syndromic surveillance for influenza in the emergency department-A systematic review. PloS One 2013;8:e73832.

39. Jung I, Kulldorff M, Kleinman KP, et al. Using encounters versus episodes in syndromic surveillance. J Publ Health 2009;31:566-72.

40. Blatt AJ. Health, science, and place: a new model. Cham: Springer International Publishing; 2015. pp 111-125.

41. Almog M, Curtis S, Copeland A, Congdon P. Geographical variation in acute psychiatric admissions within New York City 1990-2000: growing inequalities in service use? Soc Sci Med 2004;59:361-76.

42. Grinspan ZM, Abramson EL, Banerjee S, et al. People with epilepsy who use multiple hospitals; prevalence and associated factors assessed via a health information exchange. Epilepsia 2014;55:734-5. 